\title{
Hemorrhagic intramedullary solitary fibrous tumor of the conus medullaris: case report
}

\author{
Corey T. Walker, MD, ${ }^{1}$ Chiazo S. Amene, MD, ${ }^{2}$ Jeffrey S. Pannell, MD, ${ }^{2}$ \\ David R. Santiago-Dieppa, MD, ${ }^{2}$ Robert C. Rennert, MD, ${ }^{2}$ Lawrence A. Hansen, MD, ${ }^{3}$ and \\ Alexander A. Khalessi, MD, MS²
}

\begin{abstract}
'Division of Neurosurgery, Barrow Neurological Institute, St. Joseph's Hospital and Medical Center, Phoenix, Arizona; ${ }^{2}$ Division of Neurosurgery, University of California-San Diego; and ${ }^{3}$ Department of Pathology, University of California-San Diego, California

The differential diagnosis of spinal tumors is guided by anatomical location and imaging characteristics. Diagnosis of rare tumors is made challenging by abnormal features. The authors present the case of a 47-year-old woman who presented with progressive subacute right lower-extremity weakness and numbness of the right thigh. Physical examination further revealed an extensor response to plantar reflex on the right and hyporeflexia of the right Achilles and patellar reflexes. Magnetic resonance imaging of the lumbar spine demonstrated an 8-mm intramedullary exophytic nodule protruding into a hematoma within the conus medullaris. Spinal angiography was performed to rule out an arteriovenous malformation, and resection with hematoma evacuation was completed. Pathological examination of the resected mass demonstrated a spindle cell neoplasm with dense bundles of collagen. Special immunostaining was performed and a diagnosis of solitary fibrous tumor (SFT) was made. SFTs are mesenchymally derived pleural neoplasms, which rarely present at other locations of the body, but have been increasingly described to occur as primary neoplasms of the spine and CNS. The authors believe that this case is unique in its rare location at the level of the conus, and also that this is the first report of a hemorrhagic SFT in the spine. Therefore, with this report the authors add to the literature the fact that this variant of an increasingly understood but heterogeneous tumor can occur, and therefore should be considered in the differential of clinically similar tumors.
\end{abstract}

http://thejns.org/doi/abs/10.3171/2015.1.SPINE13915

KEY WORDS solitary fibrous tumor; spine; intramedullary; hemorrhage; conus medullaris; lumbar

A SOLITARY fibrous tumor (SFT) is a rare mesenchymal neoplasm most commonly found in the visceral pleura of the lungs. ${ }^{3,9}$ Extraserosal sites have been reported in the literature, including primary SFTs of the CNS. ${ }^{6,21,34}$ Specifically, within the spine there have been 46 reported cases ${ }^{1,4,5,7,8,10-20,22,23,25-33,35-37}$ in the literature since the first description in $1997 .^{1}$

Of these described tumors, the majority occur within the thoracic region of the cord, with the most common presentation being intradural extramedullary, although extensive variants have been described. Despite this diversity in presentation, only 2 cases ( 1 intramedullary, 1 intradural extramedullary) have been reported to occur within the conus medullaris. ${ }^{5,22}$

Furthermore, due to the solid nature of these neoplasms, grossly and radiographically they often resemble fibrous meningiomas or hemangiopericytomas. Yet, they are often considered to be less vascularized than hemangiopericytomas. To the best of our knowledge, there have thus been no described cases of hemorrhagic SFTs of the spine. In this report we describe a unique intramedullary SFT of the conus medullaris that developed a hemorrhage into the

ABBREVIATIONS EMA = epithelial membrane antigen; GFAP = glial fibrillary acidic protein; SFT = solitary fibrous tumor; SMA = smooth muscle actin . SUBMITTED October 15, 2013. ACCEPTED January 13, 2015.

INCLUDE WHEN CITING Published online June 26, 2015; DOI: 10.3171/2015.1.SPINE13915.

DISCLOSURE The authors report no conflict of interest concerning the materials or methods used in this study or the findings specified in this paper. 
spinal cord parenchyma. We believe the rarity of the location and hemorrhagic nature of this neoplasm present as novel findings in an increasingly understood spinal tumor.

\section{Case Report}

History

The patient was a 47-year-old woman with a history of depression and hyperlipidemia who presented to the neurology clinic with a 3-year history of constant low-back and right leg pain over the lateral aspect of her thigh. She had previously undergone workup by a neurosurgeon from another institution whose records were not provided. She had been told that she had a cystic lesion in her spinal cord based on an MRI study of the lumbar spine from 2 years prior to presentation that had been stable on repeat imaging. At this time she was referred to our neurosurgical clinic following repeat lumbar spine imaging. In the approximately 3 months between these visits, she began to experience worsening pain in her leg. This was accompanied by new-onset, progressive, right lower-extremity weakness, making ambulation difficult. She had no accompanying bowel or bladder symptoms, and denied any contralateral leg deficits.

\section{Physical Examination}

On examination in the neurology clinic, the patient was found to have decreased sensation to light touch in the posterolateral aspect of her right lower extremity, and mild knee flexion weakness. A full neurological examination was again performed on presentation to our clinic. The patient's motor examination was notable for 3/5 strength, with right ankle pronation, supination, dorsiflexion, and plantar flexion, and 4/5 strength of right hip and knee flexion and extension. All other extremities showed full strength. Sensory examination revealed decreased pain and temperature perception throughout the entire right lower extremity, with no contralateral deficits. Her reflexes were notable for mild hyporeflexia on the right Achilles tendon and patellar reflexes relative to the left. A Babinski response was positive on the right, but not on the left. Rectal examination demonstrated good tone and volition. A postvoid residual was measured and found to be normal as well.

\section{Neuroimaging Findings}

An MRI study of her lumbosacral spine was performed. Within the conus medullaris region of the spinal cord at the L-1 vertebral segment, a $2.3 \times 1.0-\mathrm{cm}$ intramedullary lesion slightly expanding the diameter of the cord could be visualized. This lesion was believed to be hematoma based on its T1 hyperintensity, T2 hypointensity, and surrounding dark T2 rim, indicating hemosiderin deposition (Fig. 1). Adjacent to the hematoma dorsomedially, an 8-mm exophytic nodule protruded into the hematoma cavity. This nodule was hypointense on T2 and enhanced homogeneously with Gd enhancement.

The primary radiological differentials for the lesion at this time included ependymoma, myxopapillary type, and intramedullary cavernous malformation. However, based on the presence of a hematoma, a strong suspicion for a vascular neoplasm guided us to perform a spinal angiogram. Spinal vessels were visualized from T-7 to L-3. No early draining vein or fistulas were present to suggest an underlying arteriovenous malformation.

\section{Operation}

The patient was taken to the operating room for hematoma evacuation and biopsy and resection of the lesion. An L-1 laminectomy was performed bilaterally with the spinous process removed and saved for later autograft. The surgical microscope was then used to open the dura mater and inspect the mass. Neurophysiological monitoring was used to measure somatosensory and motor evoked potentials and sacral root conduction. A spherical mass with an overlying venous plexus was immediately visualized following dural retraction. Superiorly and caudally to the mass, the hematoma cavity was easily seen and evacuated. At this time, a small piece of the spherical mass was resected and sent for frozen-section pathological analysis. This revealed a spindle cell tumor, probably an ependymoma or schwannoma. The decision was then made to resect the remaining portion of the tumor, which was noted to be quite firm, vascular, and infiltrative. Although there was no obvious plane noted between the mass and the spinal cord parenchyma, gross-total resection was achieved without disturbances of neurophysiological parameters. The dura was then closed. Harvested bone from the laminectomy was laid in the lateral gutters as autograft as for possible bony fusion, which was deemed reasonable given the thoracolumbar junction location. An instrumented fusion was not performed to insure that high-quality MRI studies could be obtained for follow-up scans assessing potential tumor regrowth.

\section{Pathological Findings}

As mentioned, frozen-section pathological analysis demonstrated a spindle cell tumor of unspecified type. Permanent tissue sections were stained with $\mathrm{H} \& \mathrm{E}$, which showed moderately to highly cellular interwoven and intersecting fascicles of fusiform spindle cells (Fig. 2). These cells had elongated bipolar nuclei in a collagenous background admixed with peripheral nerves. No mitoses or necrosis was identified. Spindle cell proliferation encroached on the edges and partially invaded the spinal cord parenchyma at some of the resection margins. Special staining with CD34, BCL-2, and CD99 was positive (Fig. 3). Staining with S100, glial fibrillary acidic protein (GFAP), smooth muscle actin (SMA), and epithelial membrane antigen (EMA) was negative. Therefore, based on the immunohistochemical profile and the histochemical fascicular spindle cell morphology, the lesion was consistent with SFT.

\section{Postoperative Course}

The patient did well postoperatively. Ten-day postoperative MRI studies of the lesion (Fig. 4) demonstrated evacuation of the hematoma and gross-total resection of the tumor, with no recurrence seen at 1 year (Fig. 5). Symptomatically, her pathological reflexes resolved within 2 weeks postoperatively, her right leg regained near-normal muscle strength and tone, and she was able to ambulate 


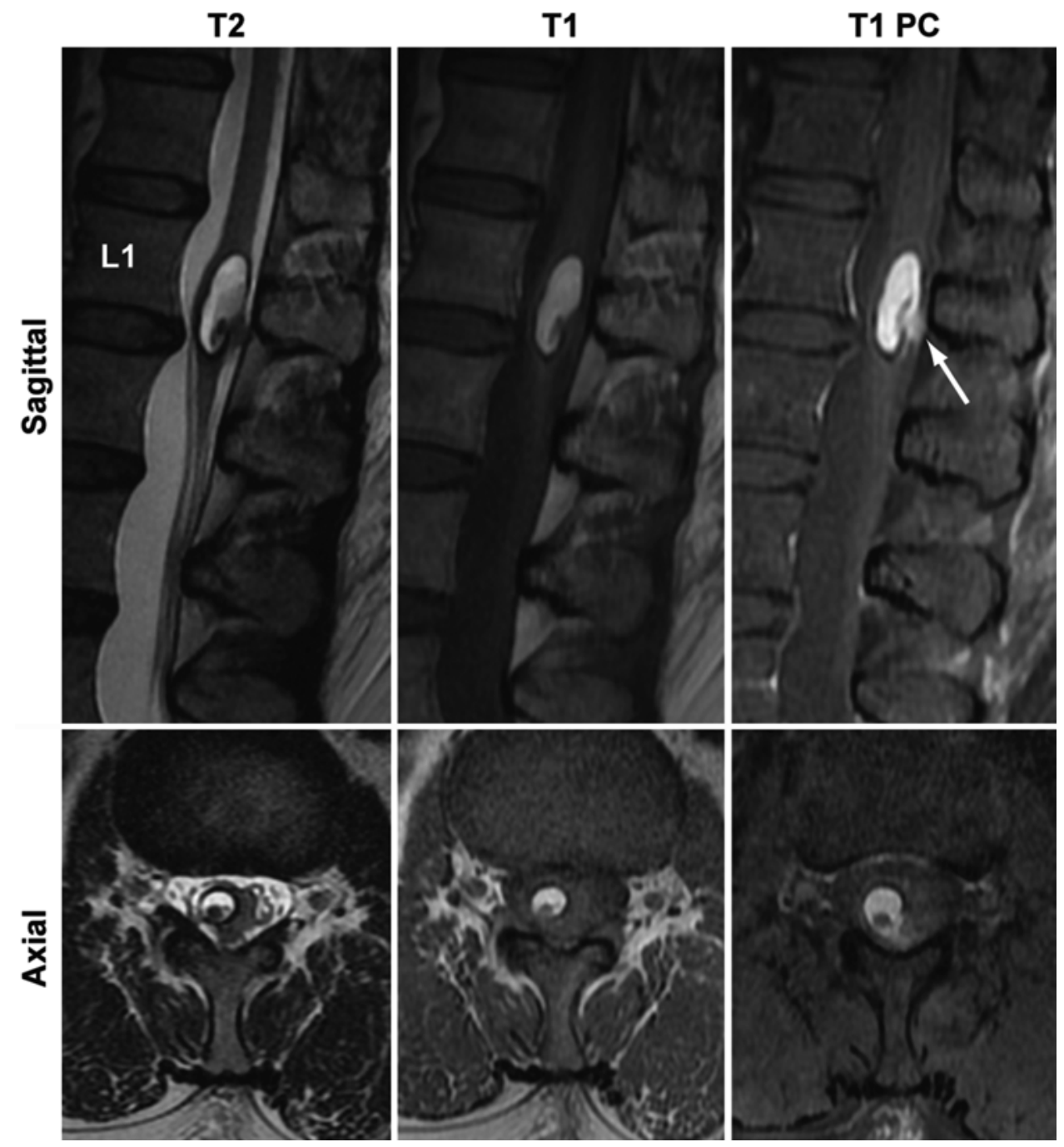

FIG. 1. Representative preoperative MRI studies demonstrating an intramedullary lesion in the conus medullaris at the L-1 vertebral level. Sagittal images demonstrate a $2.3 \times 1.0-\mathrm{cm}$ fluid collection hypointense on T2- and hyperintense on T1-weighted images, suggestive of a hematoma. A dark hemosiderin rim on T2 supports the notion that the fluid was blood. The T1 postcontrast (PC) images show an exophytic enhancing nodule $8 \mathrm{~mm}$ in diameter protruding into the hematoma cavity. Axial cuts demonstrate the location of the lesion relative to the spinal cord. The axial T2 image shows dense vascularity entering the spinal cord at the level of the lesion.

independently. These findings were stable at 1-year followup. She did, however, have some residual numbness over the lateral aspect of her right thigh, and stable neuropathic pain in that extremity. Her bowel and bladder function remained normal throughout her postoperative course.

\section{Discussion}

Central nervous system tumors possess a broad differential diagnosis. Although SFTs of the CNS occur only rarely, based on the expanding number of reports in the literature it appears that their incidence may be higher than previously suspected. As reported in this literature, these tumors appear to be somewhat heterogeneous, with varying locations and degrees of aggressiveness, and diagnosis relies almost exclusively on histological findings rather than on clinical or imaging characteristics. ${ }^{7,20}$

This case is unique for SFTs of the CNS with respect to both location and hemorrhagic nature. Although CNS SFTs can be spinal or cranial, the majority of spinal SFTs are intradural extramedullary lesions within the thoracic cord region. In fact, only 2 cases have been reported in the more distal conus medullaris, 5,22 with only 1 being intramedullary, ${ }^{5}$ as was seen in this case. Even more distal lesions can occur, however; there is 1 report of an SFT within the filum terminale. ${ }^{37}$

Regarding hemorrhage, to our knowledge this is the first time that a spinal SFT has been reported to hemorrhage into the spinal cord. This is of clinical significancewhereas SFTs are thought to be of relatively low vascularity, ${ }^{20}$ the more prominent tumor vasculature seen in this case may have led to recurrent microbleeds of the lesion, and thus contributed to the patient's progressive weakness and subacute worsening of symptoms.

This case was nonetheless similar to other intramedullary spinal SFTs with regard to a firm tumor consistency, 

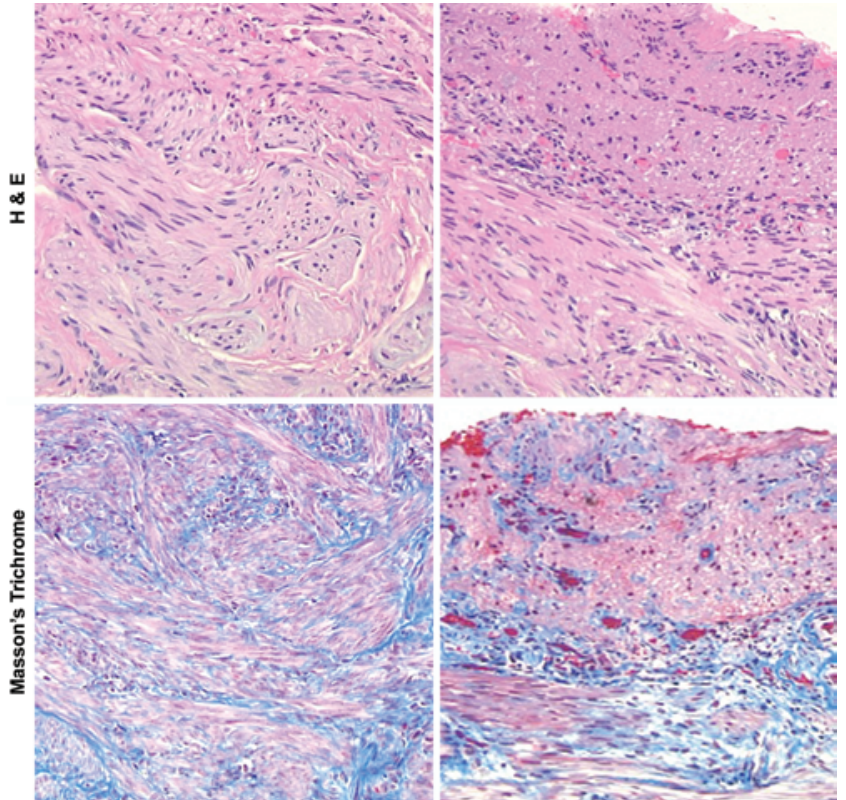

FIG. 2. Photomicrographs of resected tumor tissue prepared with histochemical stains. $\mathrm{H}$ \& $\mathrm{E}$ stains reveal a patternless fascicular neoplasm with bands of collagen that are depicted in blue by Masson's trichrome stain. These bands surround fascicles of spindle cells. Juxtaposition of the lesion situated below normal spinal cord parenchyma is depicted (right-hand panels) for both stains. Original magnification $\times 200$.

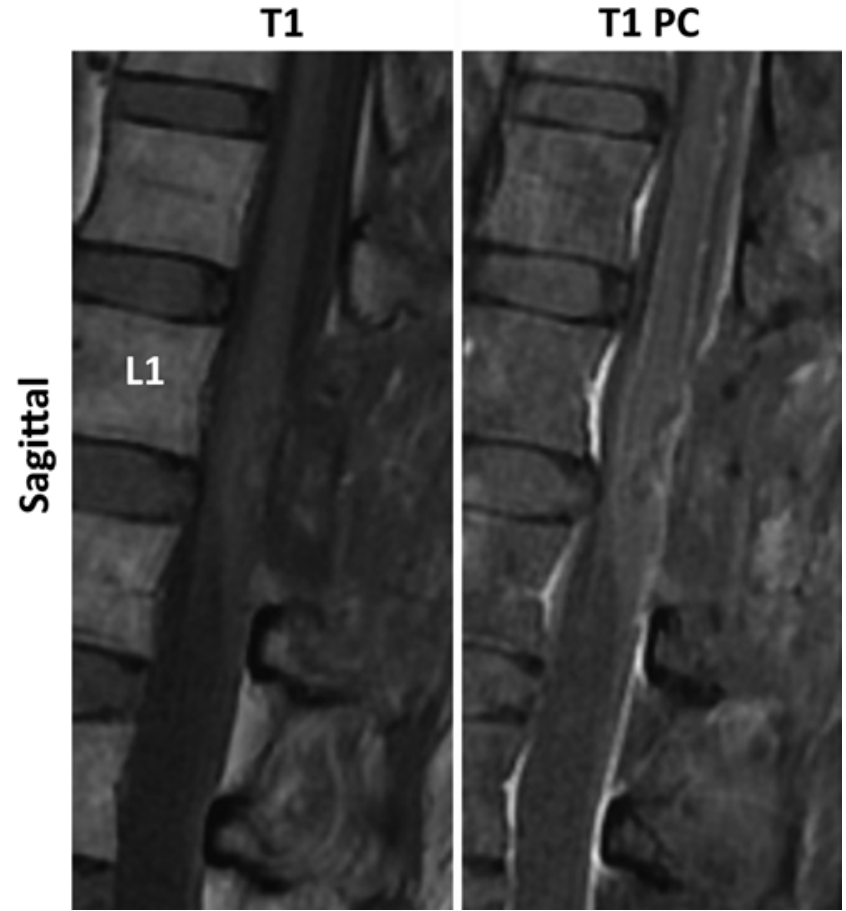

FIG. 4. Representative sagittal MRI studies obtained 10 days postoperatively demonstrate gross-total resection of the lesion and evacuation of the hematoma. As seen on the T1 postcontrast (PC) image, there is no enhancement in the region of the resected tumor.
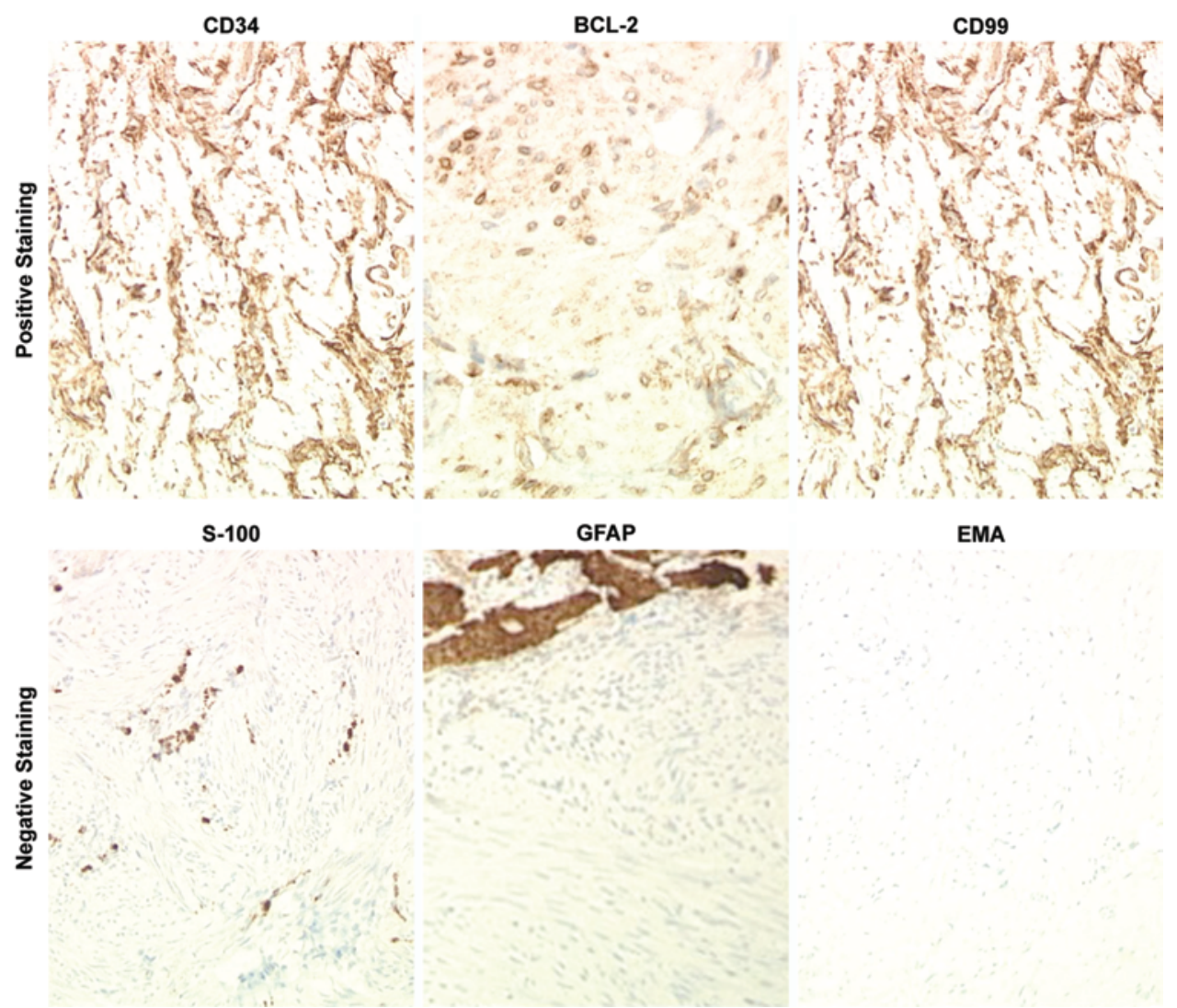

EMA

FIG. 3. Photomicrographs of resected tumor tissue prepared with special stains for pathological diagnosis. Positive special stains are shown in the top row and negative in the bottom row; tissue specimens were positive for CD34, BCL-2, and CD99 and negative for S100, GFAP, and EMA. Original magnification $\times 200$. 
T2

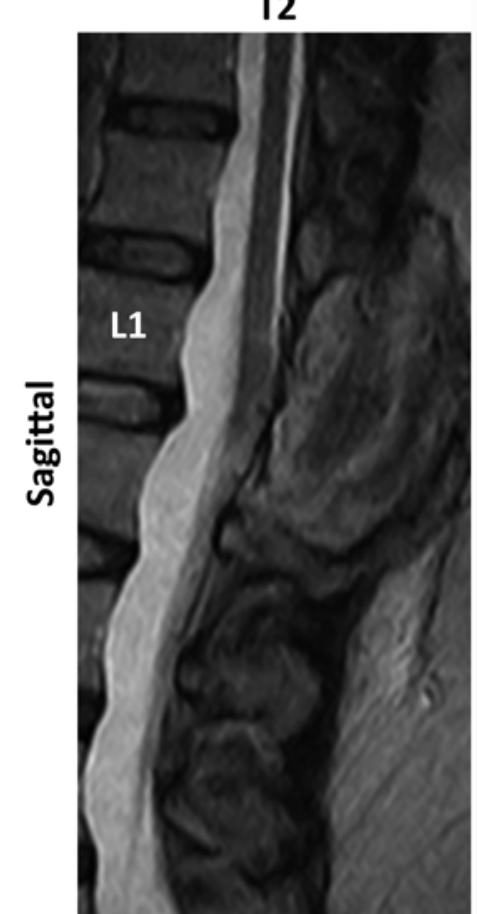

T1

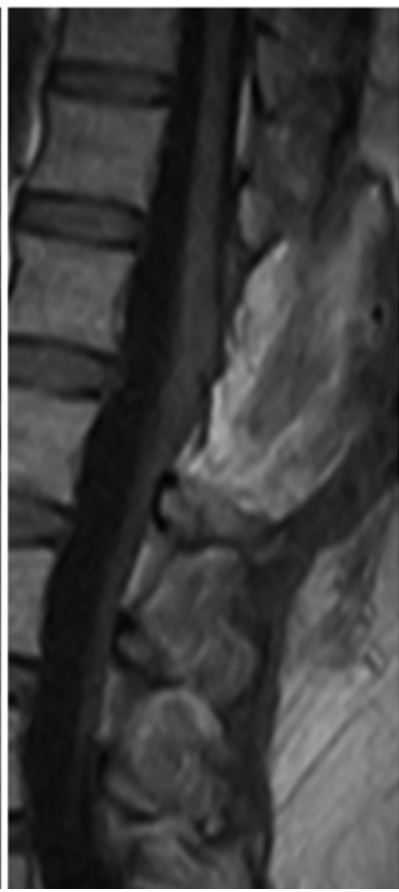

T1 PC

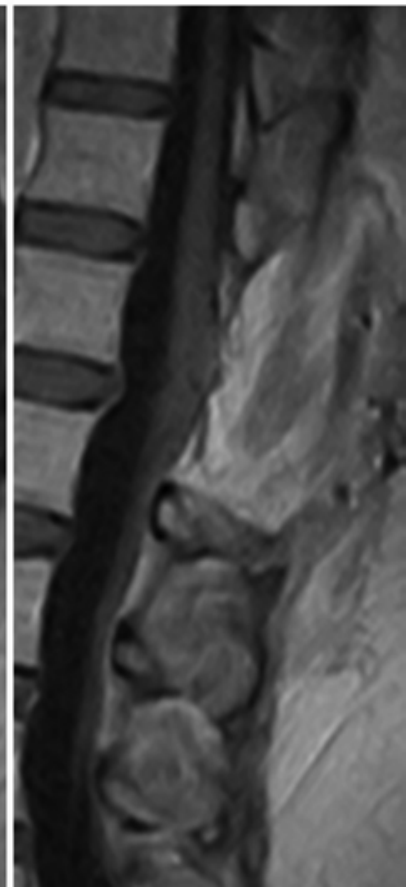

FIG. 5. Representative sagittal MRI studies obtained 1 year postoperatively demonstrate absence of tumor recurrence.

strong attachment to the cord, and exophytic nature (nearly half of intramedullary SFTs have been reported to be exophytic). ${ }^{20}$ Despite its prominent vascularity, the tumor also possessed benign histological features, including a lack of pleomorphism, high mitotic activity, or necrosis. Consequently, it is expected that the patient will not have recurrence because gross-total resection was achieved. Still, long-term data for these tumors remains sparse, and malignant transformation has been reported. ${ }^{2,24}$

In reporting this unique variant of a spinal SFT, we find that the differential diagnosis of a distal intramedullary, hemorrhagic spinal lesion should include an SFT.

\section{References}

1. Alston SR, Francel PC, Jane JA Jr: Solitary fibrous tumor of the spinal cord. Am J Surg Pathol 21:477-483, 1997

2. Bouyer B, Guedj N, Lonjon G, Guigui P: Recurrent solitary fibrous tumour of the thoracic spine. A case-report and literature review. Orthop Traumatol Surg Res 98:850-853, 2012

3. Briselli M, Mark EJ, Dickersin GR: Solitary fibrous tumors of the pleura: eight new cases and review of 360 cases in the literature. Cancer 47:2678-2689, 1981

4. Brunori A, Cerasoli S, Donati R, Giangaspero F, Chiappetta F: Solitary fibrous tumor of the meninges: two new cases and review of the literature. Surg Neurol 51:636-640, 1999

5. Carneiro SS, Scheithauer BW, Nascimento AG, Hirose T, Davis DH: Solitary fibrous tumor of the meninges: a lesion distinct from fibrous meningioma. A clinicopathologic and immunohistochemical study. Am J Clin Pathol 106:217-224, 1996

6. Caroli E, Salvati M, Orlando ER, Lenzi J, Santoro A, Giangaspero F: Solitary fibrous tumors of the meninges: report of four cases and literature review. Neurosurg Rev 27:246-251, 2004

7. Ciappetta P, D’Urso PI, Cimmino A, Ingravallo G, Rossi R,
Colamaria A, et al: Intramedullary solitary fibrous tumor of dorsal spinal cord. Neuropathology 30:273-278, 2010

8. Donnellan RB, Govender D, Chite SH, Landers AT: An unusual presentation of solitary fibrous tumor. Spine (Phila Pa 1976) 25:749-751, 2000

9. England DM, Hochholzer L, McCarthy MJ: Localized benign and malignant fibrous tumors of the pleura. A clinicopathologic review of 223 cases. Am J Surg Pathol 13:640658,1989

10. Hasegawa T, Matsuno Y, Shimoda T, Hasegawa F, Sano T, Hirohashi S: Extrathoracic solitary fibrous tumors: their histological variability and potentially aggressive behavior. Hum Pathol 30:1464-1473, 1999

11. Hwang US, Kim SB, Jo DJ, Kim SM: Intramedullary solitary fibrous tumor of cervicothoracic spinal cord. J Korean Neurosurg Soc 56:265-268, 2014

12. Jallo GI, Roonprapunt C, Kothbauer K, Freed D, Allen J, Epstein F: Spinal solitary fibrous tumors: a series of four patients: case report. Neurosurgery 57:E195, 2005

13. Kanahara T, Hirokawa M, Shimizu M, Terayama K, Nakamura E, Hino Y, et al: Solitary fibrous tumor of the spinal cord. Report of a case with scrape cytology. Acta Cytol 43:425-428, 1999

14. Kataoka H, Akiyama Y, Kubo S, Itoh H, Hamasuna R, Tajima N, et al: Solitary fibrous tumor of the spinal nerve rootlet: case report and literature survey. Pathol Int 49:826-830, 1999

15. Kawamura M, Izawa K, Hosono N, Hirano H: Solitary fibrous tumor of the spinal cord: case report and review of the literature. Neurosurgery 55:433, 2004

16. Kim TA, Brunberg JA, Pearson JP, Ross DA: Solitary fibrous tumor of the paranasal sinuses: CT and MR appearance. AJNR Am J Neuroradiol 17:1767-1772, 1996

17. Kuchelmeister KSA, Bohle RM, Kretschmer T, Richter HP, Schachenmayr W: Solitary fibrous tumor: A new differential diagnosis in surgical neuropathology. Report of two cases. Clin Neuropathol 16:270, 1997

18. Kurtkaya O, Elmaci I, Sav A, Pamir MN: Spinal solitary 
fibrous tumor: seventh reported case and review of the literature. Spinal Cord 39:57-60, 2001

19. Malek AM, Weller SJ, Price DL Jr, Madsen JR: Solitary fibrous tumor presenting as a symptomatic intraspinal mass: case report. Neurosurgery 40:844-847, 1997

20. Mariniello G, Napoli M, Russo C, Briganti F, Giamundo A, Maiuri F, et al: MRI features of spinal solitary fibrous tumors. A report of two cases and literature review. Neuroradiol J 25:610-616, 2012

21. Metellus P, Bouvier C, Guyotat J, Fuentes S, Jouvet A, Vasiljevic A, et al: Solitary fibrous tumors of the central nervous system: clinicopathological and therapeutic considerations of 18 cases. Neurosurgery 60:715-722, 2007

22. Montano N, Rigante L, Papacci F, Novello M, Lauriola L, Meglio M: Intradural extramedullary lesion of the conus medullaris. Solitary fibrous tumor. J Clin Neurosci 20:715, 765, 2013

23. Mordani JP, Haq IU, Singh J: Solitary fibrous tumour of the spinal cord. Neuroradiology 42:679-681, 2000

24. Muñoz E, Prat A, Adamo B, Peralta S, Ramón y Cajal S, Valverde C: A rare case of malignant solitary fibrous tumor of the spinal cord. Spine (Phila Pa 1976) 33:E397-E399, 2008

25. Obara Y, Matsumoto M, Chiba K, Yabe H, Toyama Y, Mukai M: Solitary cervical fibrous tumor. Case illustration. J Neurosurg 98 (1 Suppl):111, 2003

26. Ogawa T, Moriyama E, Beck H, Sonobe H: Solitary fibrous tumor of the thoracic spinal cord. Neurol Med Chir (Tokyo) 45:371-374, 2005

27. Ogungbo B, Prakash S, Kulkarni G, Bradey N, Marks SM, Scoones D: Cervical intra-/extramedullary solitary fibrous tumour. Br J Neurosurg 19:254-257, 2005

28. Pakasa NM, Pasquier B, Chambonnière ML, Morrison AL, Khaddage A, Perret AG, et al: Atypical presentations of solitary fibrous tumors of the central nervous system: an analysis of unusual clinicopathological and outcome patterns in three new cases with a review of the literature. Virchows Arch 447:81-86, 2005

29. Perry A, Scheithauer BW, Nascimento AG: The immunophenotypic spectrum of meningeal hemangiopericytoma: a comparison with fibrous meningioma and solitary fibrous tumor of meninges. Am J Surg Pathol 21:1354-1360, 1997

30. Piana S, Putrino I, Cavazza A, Nigrisoli E: Solitary fibrous tumor of the spinal nerve rootlet: report of a case mimicking schwannoma. Arch Pathol Lab Med 128:335-337, 2004

31. Pizzolitto S, Falconieri G, Demaglio G: Solitary fibrous tumor of the spinal cord: a clinicopathologic study of two cases. Ann Diagn Pathol 8:268-275, 2004

32. Robert T, Duc C, San Millán Ruíz D, Morard M: Solitary fibrous tumour with intramedullary component: case report and review of the literature. Neurol Neurochir Pol 48:144149,2014

33. Sebaaly A, Raffoul L, Moussa R: Solitary fibrous tumor of the lumbar spine: the great mimicker-report of the fifth case. Case Rep Orthop 2014:852830, 2014

34. Tihan T, Viglione M, Rosenblum MK, Olivi A, Burger PC: Solitary fibrous tumors in the central nervous system. A clinicopathologic review of 18 cases and comparison to meningeal hemangiopericytomas. Arch Pathol Lab Med 127:432-439, 2003

35. Vorster SJ, Prayson RA, Lee JH: Solitary fibrous tumor of the thoracic spine. Case report and review of the literature. $\mathbf{J}$ Neurosurg 92 (2 Suppl):217-220, 2000

36. Wang XQ, Zhou Q, Li ST, Liao CL, Zhang H, Zhang BY: Solitary fibrous tumors of the central nervous system: clinical features and imaging findings in 22 patients. J Comput Assist Tomogr 37:658-665, 2013

37. Wu Y, Huang B, Liang C: Solitary fibrous tumor of filum terminale. Acta Radiol Short Rep 1:20, 2012

\section{Author Contributions}

Conception and design: Khalessi, Walker, Amene. Acquisition of data: Pannell, Hansen. Analysis and interpretation of data: Walker. Drafting the article: Walker. Critically revising the article: Khalessi, Amene, Pannell, Santiago-Dieppa, Rennert. Reviewed submitted version of manuscript: Walker, Rennert. Approved the final version of the manuscript on behalf of all authors: Khalessi. Administrative/technical/material support: Rennert.

\section{Correspondence}

Alexander A. Khalessi, Division of Neurosurgery, University of California, San Diego, 200 W. Arbor Dr., San Diego, CA 92103. email: akhalessi@uscd.edu. 